\title{
Tectonic modeling of Konya-Beysehir Region (Turkey) using cellular neural networks
}

\author{
Ali Muhittin Albora $\left({ }^{1}\right)$, Osman Nuri Uçan $\left({ }^{2}\right)$ and Davut Aydogan $\left({ }^{1}\right)$ \\ (') Geophysical Department, Engineering Faculty, Istanbul University, Avcilar, Istanbul, Turkey \\ ${ }^{(2)}$ Electrical and Electronics Department, Engineering Faculty, Istanbul University, Avcilar, Istanbul, Turkey
}

\begin{abstract}
In this paper, to separate regional-residual anomaly maps and to detect borders of buried geological bodies, we applied the Cellular Neural Network (CNN) approach to gravity and magnetic anomaly maps. CNN is a stochastic image processing technique, based optimization of templates, which imply relationships of neighborhood pixels in 2-Dimensional (2D) potential anomalies. Here, CNN performance in geophysics, tested by various synthetic examples and the results are compared to classical methods such as boundary analysis and second vertical derivatives. After we obtained satisfactory results in synthetic models, we applied CNN to Bouguer anomaly map of Konya-Beysehir Region, which has complex tectonic structure with various fault combinations. We evaluated CNN outputs and 2D/3D models, which are constructed using forward and inversion methods. Then we presented a new tectonic structure of Konya-Beysehir Region. We have denoted $(F 1, F 2, \ldots, F 7)$ and (Konya1, Konya2) faults according to our evaluations of CNN outputs. Thus, we have concluded that CNN is a compromising stochastic image processing technique in geophysics.
\end{abstract}

Key words Cellular Neural Network $(C N N)$ - forward and inverse modeling - tectonic modeling boundary analysis - Central Turkey

\section{Introduction}

Potential-Field maps usually contain a number of structures, which are superposed on each other. For instance, a magnetic or a gravity anomaly may be composed of regional and residual anomalies. The sum of magnetic and gravity effects due to the shallow and intermediate structures is termed a residual anomaly and the effects due to deep structures is termed as regional anom-

Mailing address: Dr. Ali Muhittin Albora, Geophysical Department, Engineering Faculty, Istanbul University, 34320 Avcilar, Istanbul, Turkey; e-mail: muhittin@istanbul.edu.tr alies. In gravity and magnetic anomaly maps, border detection of geological bodies is as important as separation of residual/regional. Blakely and Simpson (1986) developed the boundary technique in border detection problem. Fedi and Quata (1998) applied the wavelet approach in separation of potential anomalies. Uçan et al. (2001) showed that the border detection problem can be solved by wavelet approach by choosing appropriate coefficients. Albora et al. (2004) applied wavelet to archeological sites and found the walls of Hittite ancient city. Fedi and Florio (2001) defined the Enhanced Horizontal Derivative Method (EHD) technique as an alternative to boundary solutions. Chua and Yang (1988) introduced an unsupervised algorithm, which is called Cellular Neural Network (CNN). CNN is a stochastic, 2D space invariant image processing technique. Cimagalli (1993) improved theoretical researches on CNN. Albora et al. (2001a,b) applied CNN for separation of regional/residual anomalies. 
Our research area, Konya-Beysehir Region, is located in SW Turkey where intercontinental active extension, lithospheric thinning and structures indicating the initial phase of a rift evolution are observed. The determination of the causative sources' boundaries of the anomaly in Konya-Beysehir is difficult since there are various source interferences, resulting erroneous location decisions. The previous studies on this area were carried out by Kocyigit (1984), Taymaz and Prince (1992); Dolmaz et al. (2003). They showed that block faults are still active. Several tectonic deformation models have been proposed by Jackson and McKenzie (1984); Eyidogan and Jackson (1985); Prince (1989); Prince and Scott (1991); Saunders et al. (1998); and Aydemir and Ates (2005).

In this paper, we first studied on a synthetic example to evaluate border detection performance of Cellular Neural Network (CNN) and then we applied this scheme to gravity anomaly of Konya-Beysehir (Turkey). 2D and 3D tectonic modeling of the considered region is also achieved using classical forward and inversion methods on profiles on the residual gravity anomaly map. We evaluated CNN outputs along with 2D/3D models and presented a new tectonic model for this region.

\section{Cellular Neural Network (CNN) approach}

Generally, neural networks fall into two main classes: 1) memoryless neural networks and 2) dynamical neural networks. Memoryless neural networks have been used for simple static problems. Dynamic models such as in Hopfield Networks (HN) and Cellular Neural Networks (CNN) have usually been designed as dynamical systems where the inputs are set to some constant values and each trajectory approaches one of the stable equilibrium points depending upon the initial state. CNN is a dynamic large-scale non-linear analog circuit, which processes signals in real time (Chua and Yang, 1988). Like cellular automata, it is made of massive aggregate of regularly spaced circuits clones, called cells, which communicate with each other directly only through its nearest neighbors (fig. 1). The adjacent cells can

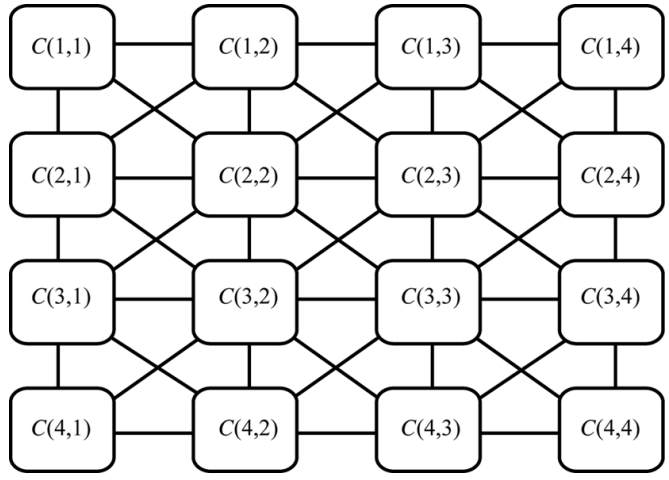

Fig. 1. A $2 D$ CNN. The circuit size is $4 \times 4$. The link between cells (squares) indicate interactions between the linked cells.

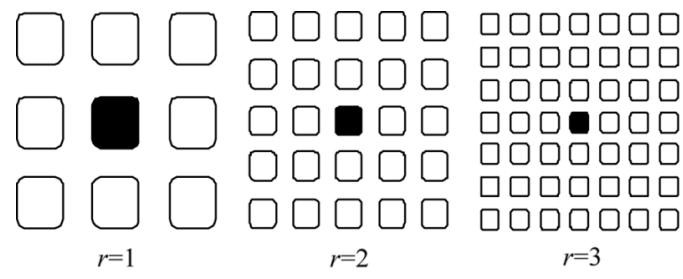

Fig. 2. The neighborhood of cell $C(i, j)$ for $r=1, r=2$ and $r=3$, respectively.

interact directly with each other. The other cells, which are not directly connected to each other, may affect each other indirectly because of the propagation effects of the continuous-time dynamics of cellular neural networks. An example of a $2 \mathrm{D} \mathrm{CNN}$ is shown in fig. 2. We call the cell on the $i^{\text {th }}$ row and $j^{\text {th }}$ column cell $C(i, j)$ as in fig. 2 . Now let us define, neighborhood of $C(i, j)$.

\subsection{Definition: r-neighborhood}

The $r$-neighborhood of a $i^{\text {th }}$ row and $j^{\text {th }}$ column cell $C(i, j)$, in a cellular neural network is defined by

$$
\begin{aligned}
& N_{r}(i, j)=\{C(k, l) \mid \max \{|k-i|,|l-j|\} \leq r \\
& 1 \leq k \leq M ; 1 \leq l \leq N\}
\end{aligned}
$$


where $r$ is a positive integer number. Figure 2 shows neighborhoods of the $C(i, j)$ cell (located at the center and shaded ) with $r=1,2$ and 3, respectively. Cells are multiple input-single output nonlinear processors all described by one, or one among several different, parametric functional. A cell is characterized by a state variable that is generally not observable as such outside the cell itself. It contains linear and non-linear circuit elements such as linear resistors, capacitors and nonlinear controlled sources. Every cell is connected to other cells within a neighborhood of itself. In this scheme, information is only exchanged between neighboring neurons and this local information characteristic does not prevent the capability of obtaining global processing. The $\mathrm{CNN}$ is a dynamical system operating in continuous or discrete time. A general form of the cell dynamical equations may be stated as follows:

$$
\begin{aligned}
& \frac{\mathrm{d} x_{i j}(t)}{\mathrm{d} t}=x_{i j}(t)+\operatorname{step}\left[-x_{i j}(t)+\sum_{k l \in N_{r}(i j)} A_{(i-k)(j-l)}(t) y_{k l}+\right. \\
& \left.+\sum_{k l \in N_{r}(i j)} B_{(i-k)(j-l)}(t) u_{k l}+I\right] \\
& y_{i j}(t)=f\left[x_{i j}(t)\right]=\frac{1}{2}\left(\left|x_{i j}(t)+1\right|-\left|x_{i j}(t)-1\right|\right)
\end{aligned}
$$

where $x, y, u, I$ denote cell state, output, input, and bias as a scalar, respectively. Step is integration step size, $j$ and $k$ cell are indices. CNN parameter values are assumed to be spaced-invariant and the nonlinear faction, which is chosen as piece-wise linear (fig. 3). $A, B$ are cloning template matrices

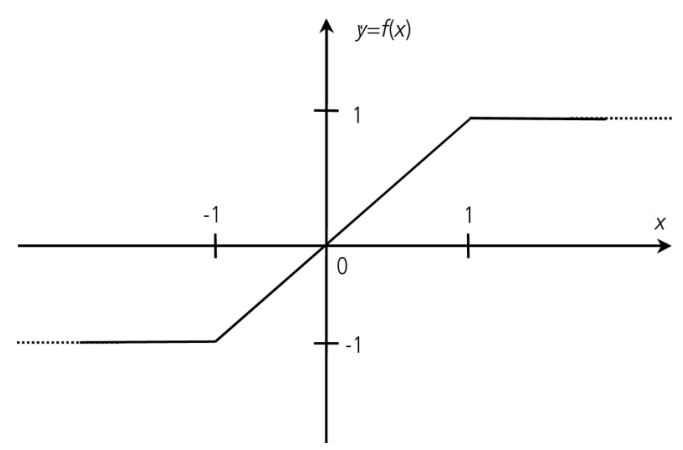

Fig. 3. Piece-wice linear output function of $\mathrm{CNN}$. which are identically repeated and $I$ scalar threshold value as

$$
A=\left[\begin{array}{ccc}
A_{-1,-1} & A_{-1,0} & A_{-1,1} \\
A_{0,-1} & A_{0,0} & A_{0,1} \\
A_{1,-1} & A_{1,0} & A_{1,1}
\end{array}\right] B=\left[\begin{array}{ccc}
B_{-1,-1} & B_{-1,0} & B_{-1,1} \\
B_{0,-1} & B_{0,0} & B_{0,1} \\
B_{1,-1} & B_{1,0} & B_{1,1}
\end{array}\right] I .
$$

The network behavior of CNN depends on the initial state of the cells activation, namely bias $I$ and on weights values of $A$ and $B$ matrices which are associated with the connections inside the well-defined neighborhood of each cell. CNN's are arrays of locally and regularly interconnected neurons, or, cells, whose global functionality are defined by a small number of parameters $(A$, $B, I)$ that specify the operation of the component cells as well as the connection weights between them. CNN can also be considered as a nonlinear convolution with the template. Here, we use discrete 2D geophysical data, then eq. (2.2) and eq. (2.3) can be rewritten as

$$
\begin{aligned}
& x_{i j}(n+1)=x_{i j}(n)+\operatorname{step}\left[-x_{i j}(n)+\right. \\
& \left.+\sum_{k l \in N_{r}(i j)} A_{(i-k)(j-l)}(n) y_{k l}+\sum_{k l \in N_{r}(i j)} B_{(i-k)(j-l)}(n) u_{k l}+I\right] \\
& y_{i j}(n)=f\left[x_{i j}(n)\right]=\frac{1}{2}\left(\left|x_{i j}(n)+1\right|-\left|x_{i j}(n)-1\right|\right)
\end{aligned}
$$

where, step is the integration step size. Since their introduction in 1988, CNN has attracted a lot of attention. The reduced numbers of connections within a local neighborhood, the principle of cloning template etc., turn out to be advantage of CNN's. Not only from a theoretical point of view, CNN has a number of attractive properties, but also there are many well-known applications such as image processing, motion detection, pattern recognition and simulation. Here we also applied this contemporary approach for the border detection of synthetic examples then Bouguer anomaly map of Konya-Beysehir Region.

\subsection{Learning algorithm}

In $\mathrm{CNN}$, we have to train $A, B, I$ templates using various optimization methods to solve the 
geophysical problems such as border detection, separation and enhancement of 2D input image. Here, weight coefficients of $A, B$ matrices and bias $I$ are optimized for synthetic examples using Recurrent Perceptron Learning Algorithm (RPLA) defined by (Guzelis and Karamahmut 1994). RPLA optimization criterion is as follows

$$
\varepsilon[w] \equiv \sum_{S=1}^{N} \varepsilon^{\prime S}[w]=\sum_{S} \sum_{i, j}\left(y_{i, j}^{S}(\infty)-d_{i, j}^{S}\right)^{2}
$$

where $y_{i, j}^{s}(\infty)$ is the steady state of output at $s$ th input vector, $d^{s}$ i,j is the desired sequence and $\varepsilon[w]$ is the total error that will be minimized. The RPLA can be described as the following set of rules.

i) Increase each feedback template coefficient, which defines the connection to a mismatching cell from its neighbor whose steady state output is same with the cell's desired output. On the contrary, decrease each feedback template coefficient, which defines the connection to a mismatching cell from its neighbor whose steady state is different from the cell's desired output.

ii) Change the input template coefficients according to the rule stated in (i) by only replacing the word of neighbor with input.

iii) Retain the template coefficients unchanged if the actually outputs match the desired outputs.

\section{Synthetic example}

As a synthetic example, gravity anomaly map of two perpendicular prisms as shown in fig. $4 \mathrm{a}$, are investigated to show the performance of CNN in border detection problem. To compare CNN performance, we applied classi-
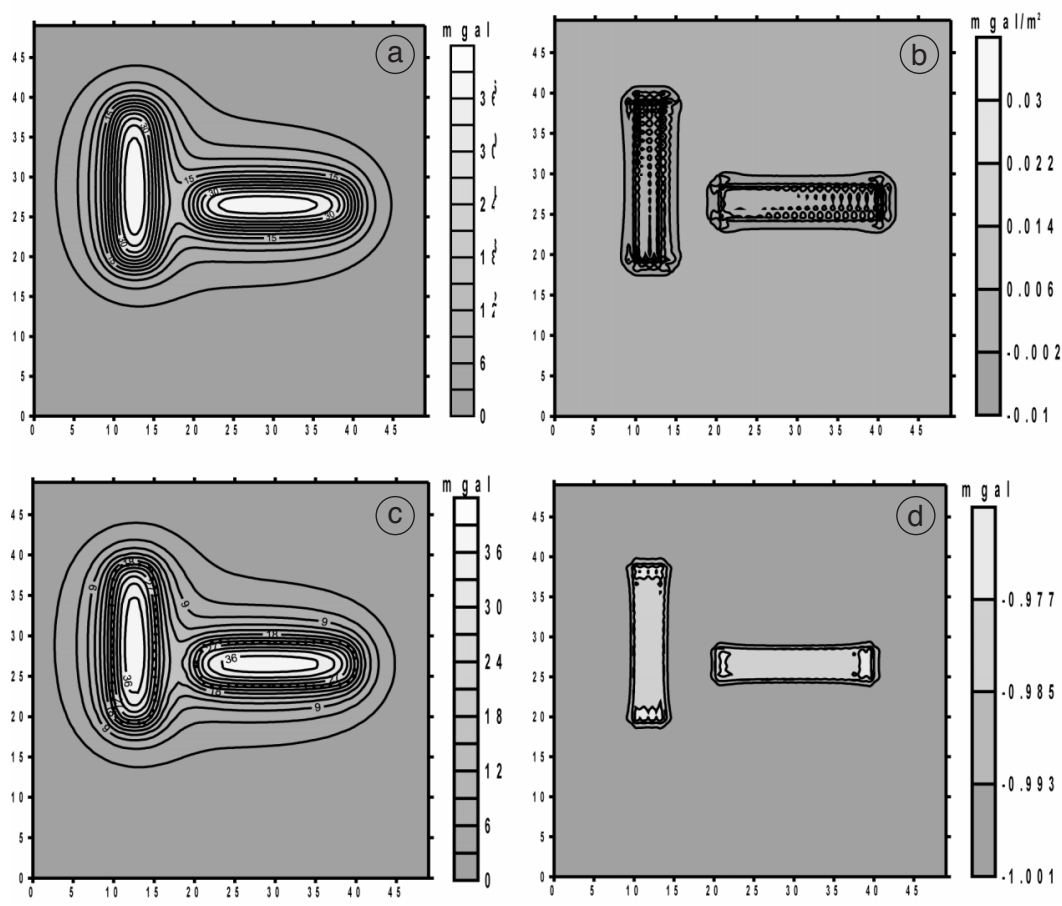

Fig. 4a-d. Two perpendicular prism model: a) gravity anomaly map (contour interval is 3 mgal); b) second vertical derivative map (contour interval is $0.008 \mathrm{mgal} / \mathrm{m}^{2}$ ); c) boundry analysis output (contour interval is $3 \mathrm{mgal}$ ); d) $\mathrm{CNN}$ output (contour interval is $0.008 \mathrm{mgal}$ ). 
cal approaches such as second vertical derivative method as in fig. 4b and boundary analysis as in fig. 4c. We have also optimized CNN templates $A, B, I$ in eqs. ((2.4)-(2.6)) using RPLA algorithm (eq. (2.7)) for synthetic example. At 50th iteration, we stopped training when the total error in eq. (2.7) is $10^{-5}$. Then CNN matrix elements of eq. (2.4) is found as

$$
A=\left[\begin{array}{ccc}
0 & 0 & 0 \\
0 & 0.01 & 0 \\
0 & 0 & 0
\end{array}\right] B=\left[\begin{array}{ccc}
-1 & -1 & -1 \\
-1 & 8 & -1 \\
-1 & -1 & -1
\end{array}\right] I=-1 .
$$

Using templates in eq. (3.1), CNN output is shown as in fig. $4 \mathrm{~d}$ and it is observed that $\mathrm{CNN}$ results are better than second vertical derivative method.

\section{Application of CNN to real data: Konya- Beysehir (Central Turkey)}

In fig. 5 our working area, Konya-Beysehir Region, is drawn in dashed lines. The most important faults in this region are as follows: Aksehir, Beysehir1, Beysehir2 and Anamas (Kocyigit, 1984). The Quaternary deposits along the Aksehir Fault are displaced about 200-300 $\mathrm{m}$, where the sense of motion along the $75^{\circ}-80^{\circ}$

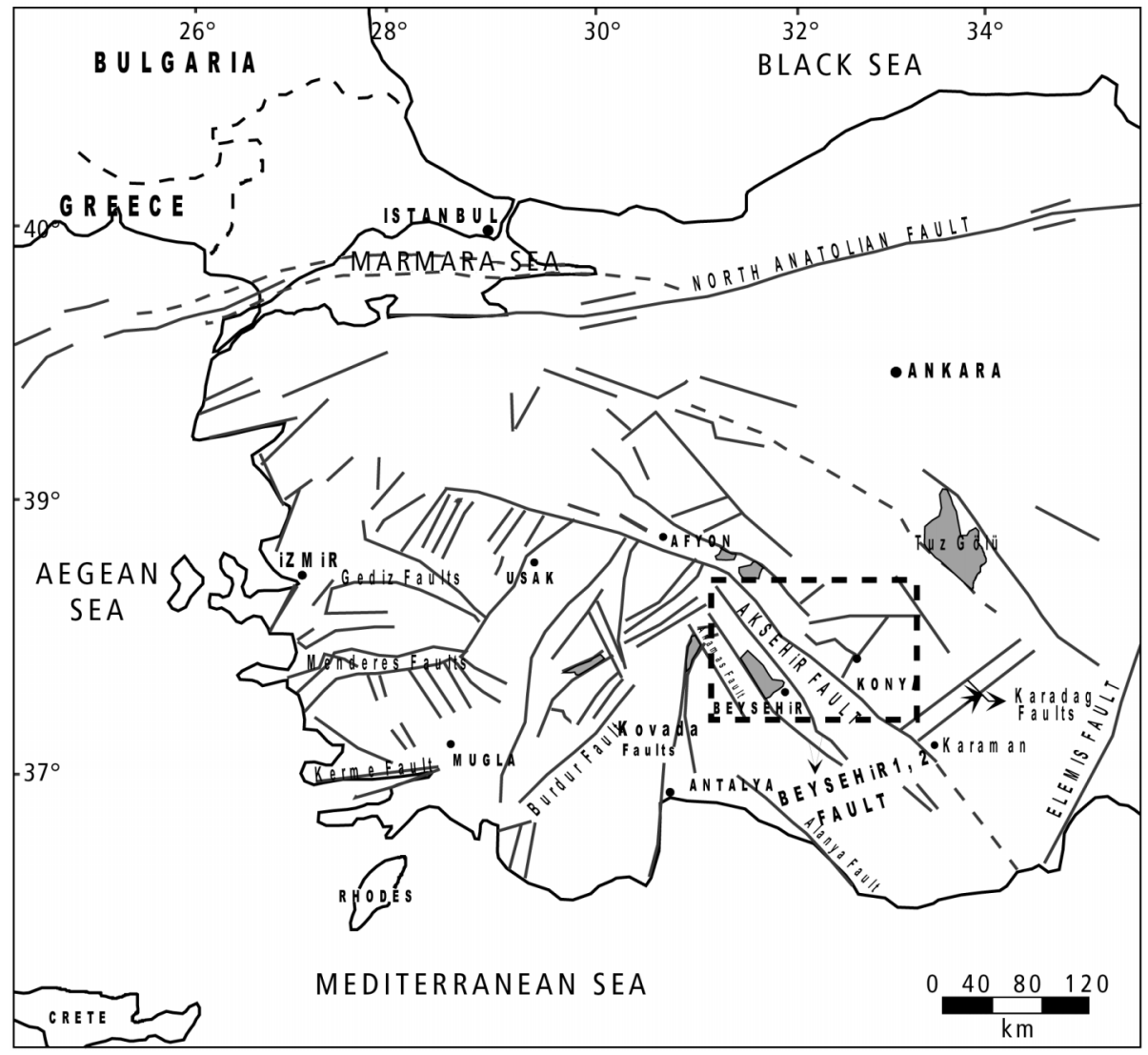

Fig. 5. Location map of the studied area and fault pattern of south-west Turkey (dashed area is modified from Kocyigit, 1984). 


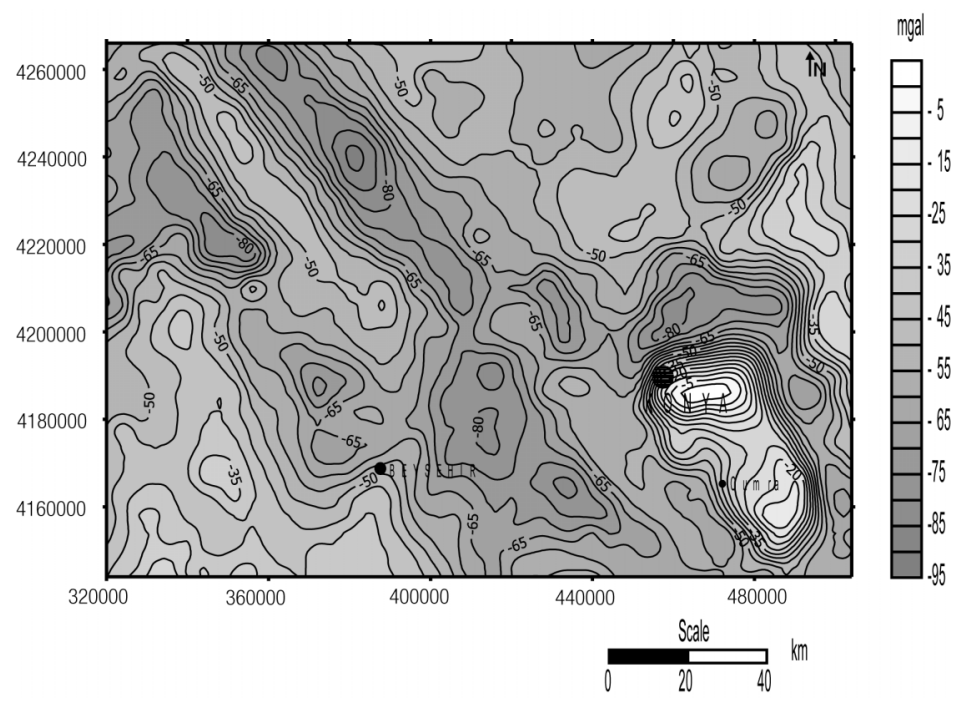

Fig. 6. Gravity anomaly map of Konya-Beysehir Region (the original map is obtained from MTA. The contour interval is $5 \mathrm{mgal}$ ).

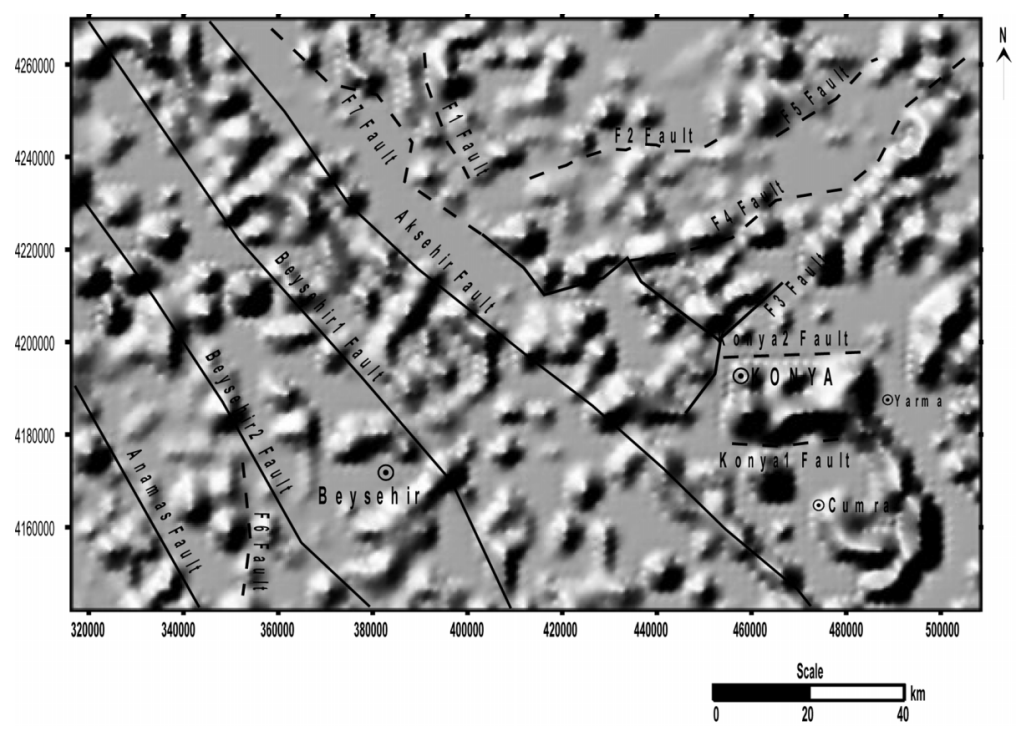

Fig. 7. Shaded Relief form of CNN output (solid lines show faults of tectonic map in fig. 5, dashed lines our proposed faults).

slope (Atalay, 1975). Aksehir Fault is an active fault (Ketin, 1968; Kocyigit and Ozacar, 2003). The Beysehir Lake is located to the SW of Aksehir Fault and the Beysehir1 and Beysehir2 faults bound the Lake. Thermal structure of crust in the studying area is investigated by Dolmaz et al. (2005) using Curie Point Depth. They found that high thermal anomaly over the 
grabens. The region is an active graben area (Kocyigit and Ozacar, 2003). These faults are causatives of important horsts and grabens. The inner side of the sediment area is fulfilled with the upper Miocene-Pliocene sedimentary rocks and alluviums (Kocyigit, 1984). To the west of Beysehir Lake, there is a listric type fault structure (Kocyigit, 1984). The faults extend NWSE, E-W and SW-NE directions. These faults become younger as passing from a horst to a graben system. The block faults are still active. Kocyigit (1984) comes to such a conclusion after observing the last phase of a faulting process where he noticed a correlation between alluvium, grabens and the lake.

In the Bouguer gravity map of MTA (The General Directorate of Mineral Exploration and Research Company of Turkey) high anomaly values in Konya and Cumra regions are present (fig. 6). It is likely that a dike with high densities causes this considered anomaly. The horsts and grabens can be clearly identified on gravity anomaly map. We applied CNN for this area and used CNN coefficients obtained by RPLA algorithm, which was previously applied to synthetic example. Using these coefficients in eq. (3.1), we obtained CNN output as shown in fig. 7. The faults, which are observed in tectonic map (fig. 5), confirmed by our CNN outputs, and are pointed out with solid lines in fig. 7. These are (Anamas, Beysehir1, Beysehir2, Aksehir) faults. We have denoted new faults: $F 1$, $F 2, \ldots, F 7$ and Konya1, Konya2 according to our CNN evaluation and placed their coordinates at our CNN output as shown in dashed lines. In between Konya1 and Konya 2 faults, there may be a magmatic intrusion.

Residual Bouguer anomaly map of KonyaBeysehir Region is prepared from Bouguer anomaly map (fig. 6) using low-pass filters (fig. 8). In fig. 8, $A_{1}-A_{2}, B_{1}-B_{2}, C_{1}-C_{2}$ and $D_{1}-D_{2}$ gravity profiles are shown in solid lines. These gravity profiles are modeled using forward modeling as in fig. $9 \mathrm{a}-\mathrm{d}$. $A_{1}-A_{2}$ and $B_{1}-B_{2}$ profiles are drawn such that they cover Aksehir, Beysehir1 and Beysehir2 faults shown in fig. 7. In forward modeling, horsts and grabens are also obtained as upward and downward blocks as shown in fig. 9a-d.

The assessment of the $A_{1}-A_{2}$ profile, which extends from SW to NE in $100 \mathrm{~km}$ length, has six different geological structures $\left(S_{1}, S_{2}, \ldots, S_{6}\right)$

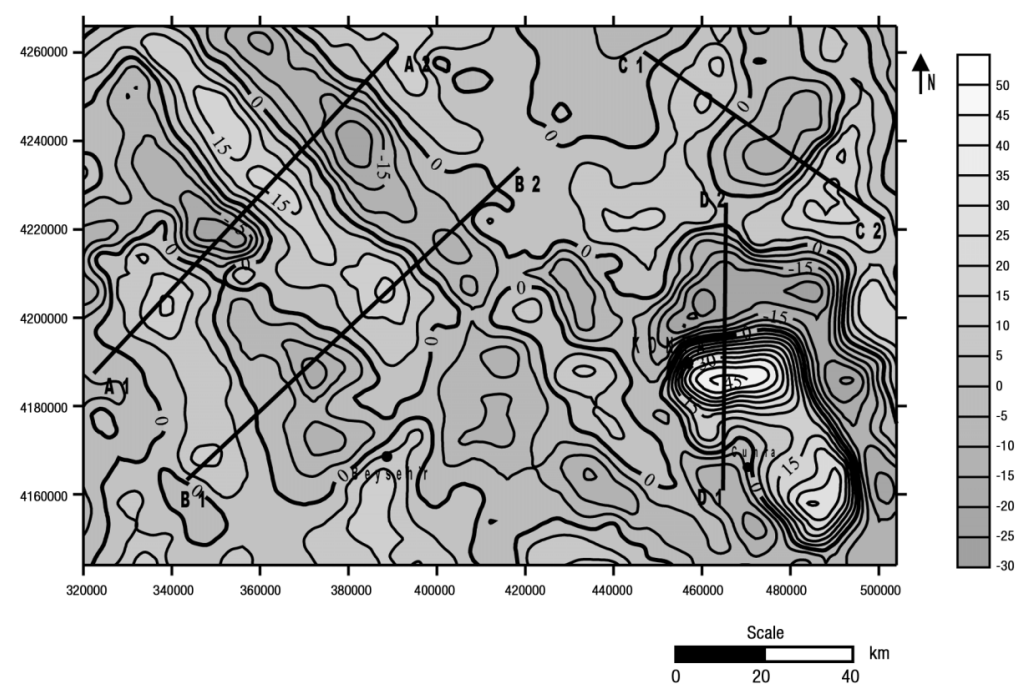

Fig. 8. Residual anomaly map obtained by low-pass filtering $\left(A_{1}-A_{2}, B_{1}-B_{2}, C_{1}-C_{2}\right.$ and $D_{1}-D_{2}$ profiles are used to construct the residual field; the contour interval is $5 \mathrm{mgal}$ ). 

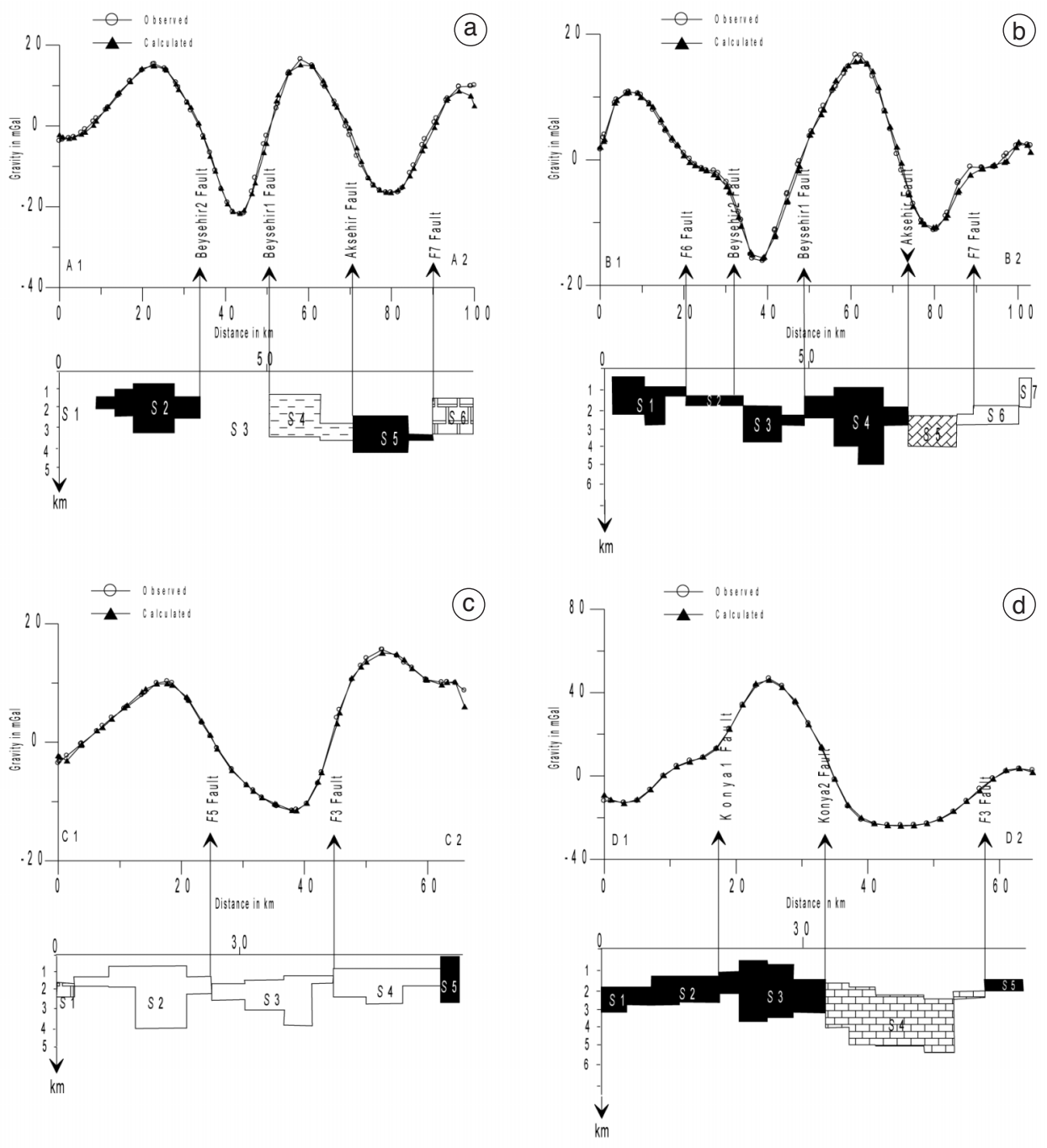

Fig. 9a-d. Anomaly profiles and estimated models. a) $A_{1}-A_{2}$ profile; b) $B_{1}-B_{2}$ profile; c) $C_{1}-C_{2}$ profile and d) $D_{1}$ $D_{2}$ profile.

(fig. 9a). The density contrasts of these geological structures are as $-0.12,0.17,-0.38,0.23$, $-0.30,0.18 \mathrm{gr} / \mathrm{cm}^{3}$, respectively. The maximum depth of $S_{2}$ is $3.4 \mathrm{~km}$ which closer to Beysehir2 Fault. It forms horst between Anamas and Beysehir2 faults. $S_{3}$ forms Beysehir graben and lies in between Beysehir1 and Beysehir2 faults with a maximum depth of $4.5 \mathrm{~km}$. $S_{4}$ has maximum depth of $3.6 \mathrm{~km}$ pointing out a horst between
Beysehir1 and Aksehir faults. $S_{5}$ structure forms a graben with maximum depth of $4.5 \mathrm{~km}$ and is bounded by Aksehir Fault as shown in fig. 7. Yet another parallel fault $F 7$, in NE of Aksehir Fault is shown in dash lines in the same figure. This fault is parallel to Aksehir Fault and tends to NW. Although, no evidences for NW continuation of this fault are given in Kocyigit (1984) our CNN output clearly reveal this continuity. 
The length of $B_{1}-B_{2}$ profile in fig. $9 \mathrm{~b}$ is 103 $\mathrm{km}$. We estimated seven different geological structures $\left(S_{1}, S_{2}, \ldots, S_{7}\right)$ in this $B_{1}-B_{2}$ profile. The density contrasts are calculated as follows: 0.15 , $-0.05,-0.33,0.15,-0.28,-0.01$ and $0.10 \mathrm{gr} / \mathrm{cm}^{3}$, respectively. $S_{1}$ with maximum depth of $2.8 \mathrm{~km}$ forms a horst located to the NE at Anamas Fault. F6 Fault lies in between Anamas and Beysehir2 faults. We estimated a similar geological structure $S_{2}$ with $1.8 \mathrm{~km}$ maximum depth, which is between Anamas and Beysehir2 faults. $S_{3}$ structure is a graben with maximum depth of $4.2 \mathrm{~km}$ and lies in between Beysehir2 and Beysehir1 faults. $S_{4}$ is a horst with maximum $5.2 \mathrm{~km}$ depth and lies in between Beysehirl and Aksehir faults. In $B_{1}-B_{2}$ profile, there is a $S_{5}$ geological structure forming Aksehir graben and has $4 \mathrm{~km}$ maximum depth. $S_{6}$ and $S_{7}$ are to the east of $F 7$ Fault.

$C_{1}-C_{2}$ profile length is $66 \mathrm{~km}$ located to the north of Konya Region extending in NW-SE direction as shown in fig. 9c. From this profile, we estimated five different geological structures $\left(S_{1}\right.$, $\left.S_{2}, \ldots, S_{5}\right)$. The density contrasts were calculated as follows from structure $S_{1}$ to $S_{5}$ : $-0.30,0.10$, $-0.18,0.24,0.13 \mathrm{gr} / \mathrm{cm}^{3}$, respectively. At CNN output, in fig. 7, a horst is also observed and $S_{2}$ structure is limited by F5 Fault in NW direction. The maximum depth of $S_{2}$ structure is found as 4

\section{(a)}
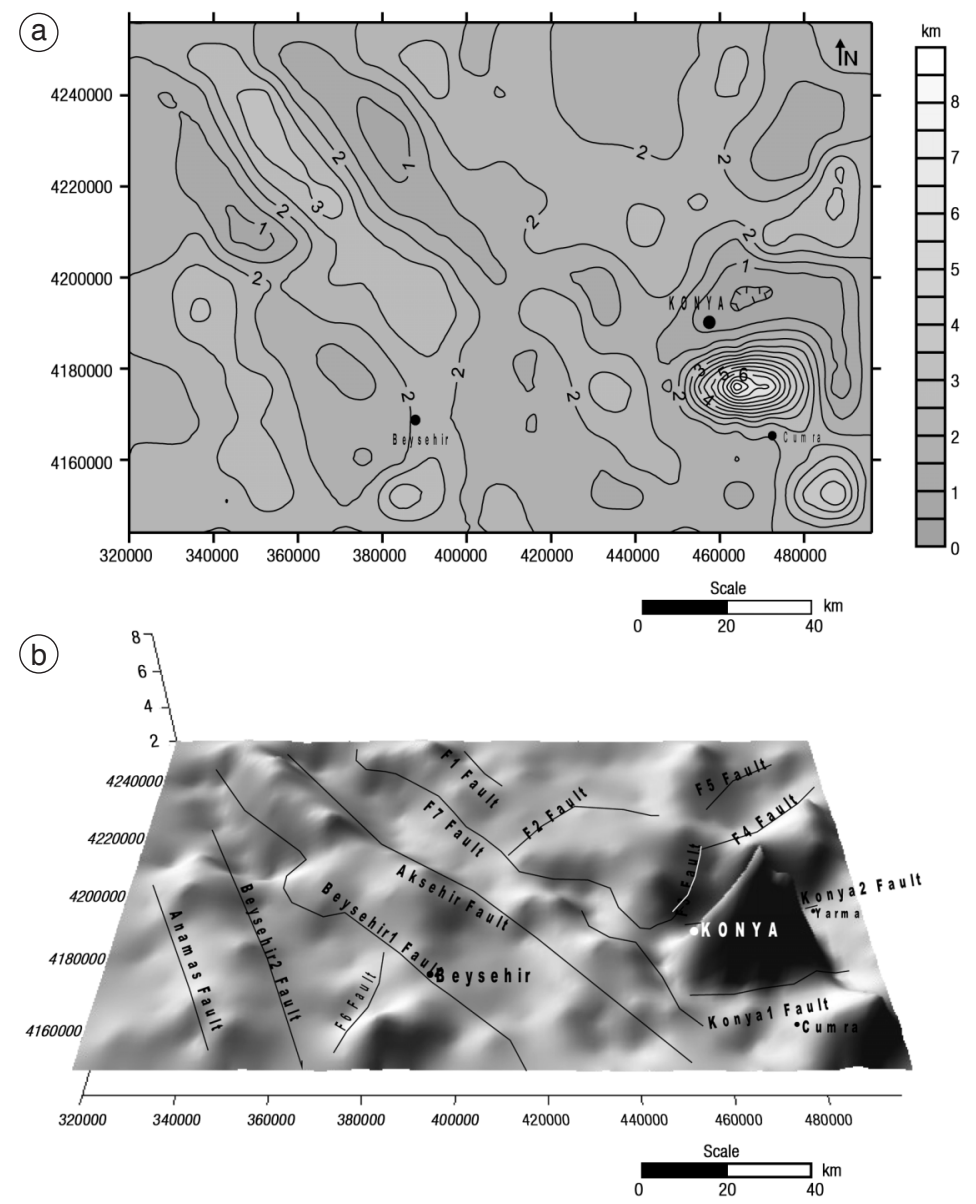

Fig. 10a,b. a) 3D estimated model of the studied area; b) 3D image of the model (the contour interval is $2.5 \mathrm{~km}$ ). 
$\mathrm{km}$. In fig. 9c, $S_{3}$ structure is a graben with maximum depth $3.8 \mathrm{~km}$ that lies between $F 5$ and $F 3$ faults. After modeling, we have found a horst structure and this geological structure is $S_{4}$, which has $2.7 \mathrm{~km}$ maximum depth. $\mathrm{NW}$ side of $S_{4}$ is bounded by $F 3$ fault.

$D_{1}-D_{2}$ profile in fig. $9 \mathrm{~d}$, has $65 \mathrm{~km}$ length and is taken in such a way from south to north passing all over Konya Region. This profile is being studied by five different geological structures $\left(S_{1}\right.$, $\left.S_{2}, \ldots, S_{5}\right)$. The related density contrasts are as follows: $-0.5,0.12,0.5,-0.30,0.45 \mathrm{gr} / \mathrm{cm}^{3}$, respectively. $S_{1}$ is under the effect of Aksehir graben. The maximum depth is $3 \mathrm{~km}$. The fault borders of Konya1 and Konya2 are well defined by CNN, which lie to the south and north of Konya, respectively. $S_{2}$ numbered geological structure is in the south of Konyal fault and has $2.8 \mathrm{~km}$ depth. The geological structure, $S_{3}$ horst is in between Konya1 and Konya2 faults at fig. 9d. Ates and Kearey (2000) have calculated the depth of this structure using their power spectrum analysis and estimated as $6.76 \mathrm{~km} . S_{3}$ structure lies in between Konya2 and $F 3$ faults. $S_{4}$ is in between Konya2 and $F 3$ faults. It starts with $5.2 \mathrm{~km}$ depth and shallows to $2.5 \mathrm{~km}$ as tends to $F 3$ fault.
We also modeled the residual gravity anomaly (fig. 8) in this area, using GRAV3DIN software program of Rama Rao et al. (1999). This method calculates the values of depth and modifies them iteratively until a best fit is achieved between the observed and calculated values. In 3D analysis, the residual anomaly map is sampled at 15 equispaced profiles with $8 \mathrm{~km}$ interval spacing. The density contrast between anomalous body and the medium is to the value of $0.5 \mathrm{~g} / \mathrm{cm}^{3}$. The resulting 3D model is shown in fig 10a,b. The 3D depth map (fig. 10b) has similar results with CNN outputs as shown in fig. 7. As a result, we have proposed a new tectonic map and denoted $F 1, F 2, \ldots, F 7$ and Konya1, Konya2 faults.

\section{Conclusions}

In this paper, we proposed Cellular Neural Network (CNN) for solution of an important problem such as border detection in geophysics. We applied CNN approach in border detection of geological structures for synthetic example and real data. First, we have used synthetic example of two perpendicular prisms and borders are detected by second vertical derivative $\mathrm{CNN}$.

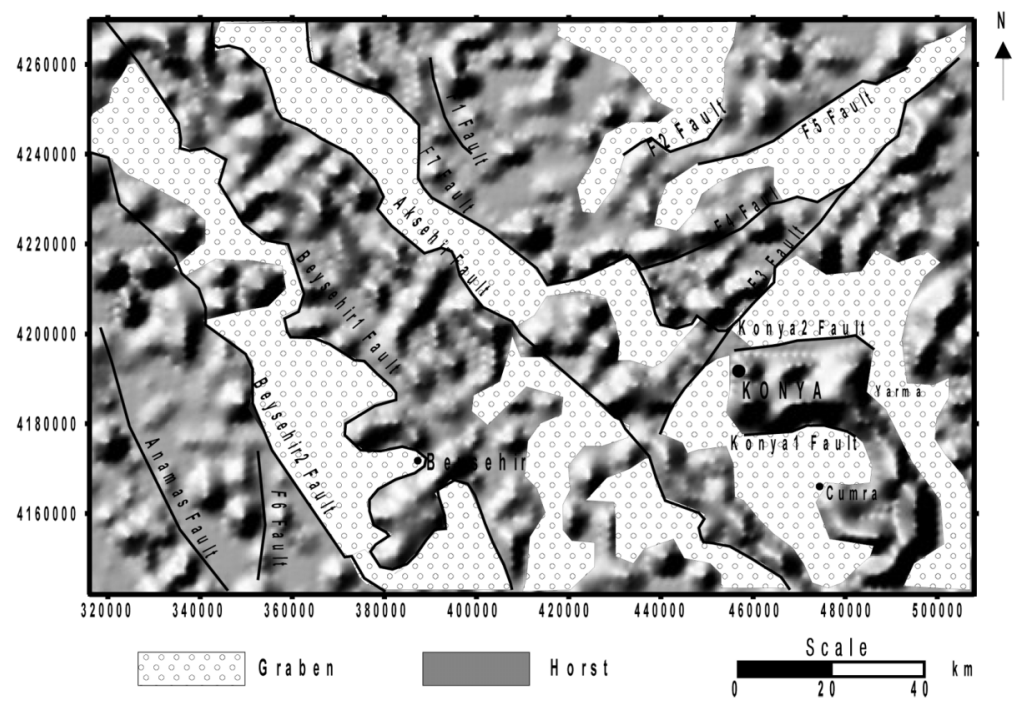

Fig. 11. Proposed tectonic map of the studied area. 
In synthetic example, $\mathrm{CNN}$ outputs have similar results with boundary techniques as in fig. 4, thus we can conclude that $\mathrm{CNN}$ is a compromising approach. CNN output of Konya-Beysehir gravity anomaly map are shown in fig. 7. Anamas, Beysehir1, Beysehir2, Aksehir and our defined faults, which are observed at CNN output, are confirmed with previous tectonic studies. We forward modeled the profiles of residual anomaly map and geological structure of this region as in fig. 9. We also estimated depth of these geological bodies. The faults extend from NW to SE direction as in fig. 10b. We have obtained a new tectonic map after evaluation of CNN outputs, previous tectonic maps, 2D and 3D forward modeling (fig. 11). We also found out a horst structure in among Anamas and Beysehir faults in tectonic map studies. Beysehir graben is observed in between Beysehir2 and Beysehirl faults. A horst structure on the NE direction of this graben is detected in between Beysehir1 and Aksehir faults. Aksehir graben is seen in between Aksehir fault and our defined $F 7$ faults. Around Aksehir graben, another horst and graben structures are seen in NE direction. In the SE part of our tectonic map, there is a graben in between Aksehir and Konya faults and there is a horst structure between Konya1,2 faults. A graben between Konya2 and our defined $F 3$ fault is observed. Also there is a horst structure in $F 3$ and $F 4$ fault area. There is also a graben in between $F 4$ and $F 5$ faults as in fig. 11. As a result, we applied CNN to border detection of gravity anomaly map of KonyaBeysehir Region and after evaluation of CNN, tectonic studies and forward modeling of profiles, we proposed a new tectonic map with new defined horsts, grabens and faults. We denoted $(F 1, F 2, \ldots, F 7)$ and (Konya1, Konya2) faults according to our CNN evaluations. As a conclusion, a new tectonic map of this region is proposed as in fig. 11 .

\section{Acknowledgements}

This work was supported by the Research Fund of the University of Istanbul (Project No: 1539/16012001). We thank Technical Ore Research of Turkey (MTA) for their gravity map.

\section{REFERENCES}

Albora, A.M., O.N. UÇAn, A. OZMEN and O. Tulay (2001a): Evaluation of Sivas-Divrigi Region Akdag iron ore deposits using cellular neural network, J. Appl. Geophys., 46, 129-142.

AlborA, A.M., O.N. UÇAN and A. OZMEN (2001b): Residual separation of magnetic fields using a cellular neural network approach, Pure Appl. Geophys., 158, 1797-1818.

Albora, A.M., Z.M. HisARLi and O.N. UÇAN (2004): Application of wavelet transform to magnetic data due to ruins of Hittite civilization in Turkey, Pure Appl. Geophys., 161, 907-930.

ATALAY, I. (1975): The effects of tectonic movements on the geomorphology of Sultandag, Geol. Soc. Turkey Bull., 18, 21-26.

Ates, A. and P. KeARey (2000): Interpretation of gravity and aeromagnetic anomalies of the Konya Region, south central Turkey, J. Balkan Geophys. Soc., 3, 37-44.

Aydemir, A. and A. ATES (2005): Preliminary evaluation of Central Anatolian basins in Turkey by using the gravity and magnetic data, J. Balkan Geophys. Soc., 8, 7-19.

Blakely, R.J. and R.W. Simpson (1986): Approximating edges of source bodies from aeromagnetic or gravity anomalies, Geophysics, 51, 1494-1498.

ChuA, L.O. and L. YANG (1988): Cellular neural networks: theory, IEEE Trans. on Circuits and Systems, 35, 12571272.

Cimagalli, V. (1993): Cellular neural networks: a review, in Proceedings of Sixth Italian Workshop on Parallel Architectures and Neural Networks, May 1993, Italy, 12-14.

DolmaZ, M.N., Z.M. Hisarli and N. Orbay (2003): Interpretation of Bouguer gravity data of Burdur Basin, Istanbul Univ. Engineering Fac. Earth Sci. J., 16, 23-32.

Dolmaz, M.N., T. UstaOMER, Z.M. Hisarli and N. Orbay (2005): Curie point depth variations to infer thermal structure of the crust at the African-Eurasian convergence zone, SW Turkey, Earth Planet. Space, 57, 1-11.

EyIDOGAN, H. and J.A. JACKSON (1985): A seismological study of normal faulting in the Demirci, Alasehir and Gediz earthquakes of 1969-1970 in Western Turkey: implications for the nature and geometry of deformation in the continental crust, Geophys. J. R. Astron. Soc., 81, 569-607.

FEDI, M. and G. Florio (2001): Detection of potential fields source boundaries by enhanced horizontal derivative method, Geophys. Prosp., 49, 40-58.

FEDI, M. and T. QUATA (1998): Wavelet Analysis for the regional-residual and local separation at potential field anomalies, Geophys. Prosp., 46, 507-525.

Guzelis, C. and S. Karamahmut (1994): Recurrent Perceptron learning algorithm for completely stable cellular neural networks, in Proceedings of the Third IEEE International Workshop on Cellular Neural Network and Applications, 177-182.

JACKSON, J.A. and D. MCKenZIE (1984): Active tectonics of the Alpine-Himalayan Belt between Western Turkey and Pakistan, Geophys. J. R. Astron. Soc., 77, 185-264.

Ketin, I. (1968): The correlation between main earthquakes and tectonic statue, Ore Tech. Res. Inst. J., 71, 129-134.

KocYIGIT, A. (1984): Intraplate neotectonic development in southwestern Turkey and adjacent areas, Bull. Geol. Soc. Turkey, 27, 1-16. 
Kocyigit, A. and A. OZACAR (2003): Extensional neotectonic regime through the NE edge of the outer Isparta Angle, SW Turkey: new field and seismic data, Turkish J. Earth Sci., 12, 67-90.

Price, S. (1989): Sedimentation and neotectonics of the Burdur Region, SW Turkey, Ph.D. Thesis, University of Leicester, U.K.

Price, S. and B. ScotT (1991): Pliocene Burdur Basin, SW Turkey: tectonics, seismicity and sedimentation, J. Geol. Soc., 148, 345-354.

Rama RaO, P., K.V. Swamy and I.V. RadHakrishna MurTY (1999): Inversion of gravity anomalies of 3D density interfaces, Comput. Geosci., 25, 887-896.

Saunders, P., K. Priestley and T. TAYmaz (1998): Varia- tions in the crustal structure beneath Western Turkey, Geophys. J. Int., 134, 373-389.

TAYMaZ, T. and S. PRICE (1992): The 1971 May 12 Burdur earthquake sequence, SW Turkey: a synthesis of seismological and geological observations, Geophys. J. Int., 108, 589-603.

UÇAN, O.N., A.M. Albora and Z.M. HisArli (2001): Comments on the gravity and magnetic anomalies of Saros Bay using wavelet approach, Mar. Geophys. Res., 22 (4), 251-264.

(received March 6, 2006; accepted September 6, 2006) 